\title{
PENGUKURAN KEPUASAN NASABAH MELALUI KUALITAS PELAYANAN PT. BNI SYARIAH KC. CIPUTAT DENGAN METODE IMPORTANCE PERFORMANCE ANALYSIS (IPA) \& METODE COSTUMER STATISFACTION INDEX (CSI)
}

\author{
Zakiah Attamimi \\ Fakultas Ekonomi dan Bisnis UIN Syarif Hidayatullah Jakarta \\ zaattamimi@gmail.com
}

Ay Maryani

Fakultas Ekonomi dan Bisnis UIN Syarif Hidayatullah Jakarta ay.maryani@gmail.com

\begin{abstract}
According to research on the comparative quality of service of conventional banks and Islamic banks it is stated that there are differences between the average value of service quality in conventional banks and Islamic banks, where the average value of conventional bank service quality is higher than that of Islamic banks, and according to judgment by Market Research Indonesia (MRI)there are 5 sharia banks that have won the Banking Service Excellence Awards and BNI Sharia is the second bank to receive an award from the Banking Service Excellence Awards where the assessment is assessed from this ranking by measuring the performance aspects of staff, security guards, customer service, and tellers. Whereas the assessment of physical aspects is assessed from the banking hall, convenience, automated teller machines performance, and e-channel services (sms, mobile, internet banking).Therefore this paper analyzes the level of customer satisfaction through the service quality of BNI Sharia Ciputat Branch Office. This research uses a non probability sampling method. The level of satisfaction measured by using Importance Performance Analysis (IPA) and Costumers Statisfaction Index (CSI). The respondents in this study were customers of BNI Sharia Ciputat Branch Office who once received service at BNI Sharia Ciputat Branch Offic. The results of the study show that customers are satisfied with the services of BNI Sharia Ciputat Branch Offic with a CSI level of 79.34\%. Based on the Importance Performance Analysis (IPA), 5 attributes are categorized as "improvement priorities", and 13 attributes are categorized as "maintain performance". In other hand, there are 3 attributes that are categorized as "excessive" and 9 attributes as "low priority". Then the average value of the suitability/difference of all service attributes of BNI Sharia Ciputat Branch Office is minus 0.14 .

Keywords: Customer Satisfaction, Service Quality, Importance Performance Analysis (IPA) and Costumers Statisfaction Index (CSI).
\end{abstract}

ABSTRAK: Berdasarkan hasil penelitian perbandingan kualitas pelayanan bank konvensional dan bank syariah dinyatakan bahwa terdapat perbedaan atara nilai rata-rata kualitas pelayanan pada bank konvensional dengan bank syariah, dimana nilai rata-rata kualitas pelayanan bank konvensional lebih tinggi dibandingkan bank syariah dan berdasarkan penilaian yang dilakukan oleh Market Research Indonesia (MRI)terdapat 5 bank syariah peraih penghargaan Banking Service Excellence Awards dan BNI Syariah merupakan bank kedua yang meraih penghargaan dari Banking ServiceExcellence Awards dimana penilaian yang dinilai dari penentuan peringkat ini yaitu dengan pengukuran aspek kinerja dari staff, satpam, costumer service, dan teller. Sedangkan penilaian aspek fisik dinilai dari banking hall, kenyamanan, kinerja ATM, dan layanan e-channel (sms, mobile, internet banking).Paper ini menganalisis tingkat kepuasan pelanggan melalui kualitas pelayanan Bank BNI Syariah KCP. Ciputat. Ini menggunakan metode non probability sampling. Tingkat kepuasan diukur dengan menggunakanImportance Performance Analysis (IPA)dan Costumers Statisfaction Index (CSI).Adapun responden pada penelitian ini adalah nasabah Bank BNI Syariah KCP. Ciputat yang pernah mendapatkan layanan pada Bank BNI Syariah KCP. Ciputat Hasil penelitian menunjukkan bahwa pelanggan puas dengan layanan dari Bank BNI Syariah KCP. Ciputat dengan tingkat CSI sebesar 79,34\%. Berdasarkan Importance Performance Analysis (IPA), 5 atribut dikategorikan sebagai "prioritas perbaikan", dan 13 atribut dikategorikan sebagai "pertahankan prestasi". Selanjutnya, ada 3 atribut yang dikategorikan "berlebihan" dan 9 atribut adalah sebagai "prioritas rendah". Kemudian rata-rata nilai kesesuaian/selisih dari seluruh atribut pelayanan Bank Bank BNI Syariah KCP. Ciputat adalah minus 0,14.

Kata Kunci: Kepuasan Pelanggan, Kualitas Pelayanan, Importance Performance Analysis (IPA) dan Costumers Statisfaction Index (CSI). 


\section{PENDAHULUAN}

Mengamati realita perkembangan bank syariah di Indonesia hingga saat ini, tantangan-tantangan yang dihadapi oleh perbankan syariah merupakan hal yang mendesak untuk dihadapi dengan berbagai macam stategi, terutama strategi pemasaran. Tantangan-tantangan tersebut timbul karena bank syariah belum sepenuhnya aktif dalam memanfaatkan peluang-peluang bisnis yang akan dijadikan strategi dalam memasarkan produk dan jasanya yang tentunya akan sangat mempengaruhi performa suatu bank syariah. Hal itu bisa terlihat dari pangsa pasar bank syariah yang masih sangat kecil jika dibandingkan dengan total pangsa pasar perbankan nasional. Total pangsa pasar Bank Syariah di Indonesia masih berkisar sekitar 5,70\% pada bulan juni $2018^{1}$.

Dari data penilaian oleh Market Research Indonesia (MRI) terdapat 5 bank syariah peraih penghargaan Banking Service Excellence Awards bank BNI Syariah merupakan bank kedua yang meraih penghargaan dari Banking Service Excellence Awards dimana penilaian yang dinilai dari penentuan peringkat ini yaitu dengan pengukuran aspek kinerja dari staff mulai dari satpam, costumer service, dan teller. Sedangkan penilaian aspek fisiknya dinilai dari banking hall, kenyamanan, kinerja ATM, dan layanan $e$ channel (sms, mobile, internet banking) ${ }^{2}$.

Lembaga-lembaga keuangan islam tidak cukup hanya sekedar mengandalkan fanatisme-emosional ummat. Andalan demikian sangat bersifat temporer karena reaktif dan justru bisa menimbulkan bumerang bagi dirinya sendiri maupun bagi ummat islam. Berkenaan dengan masalah ini maka pengenalan, propaganda, sosialisasi dan pembudayaan lembaga-lembaga keuangan islam (baik secara langsung melalui proses pendidikan dan pengajaran) haruslah dilengkapi dengan pendekatan sentiment universal ${ }^{3}$.

Berdasarkan realita yang ada, menurut penelitian tentang perbandingan kualitas pelayanan bank konvensional dan bank syariah dinyatakan bahwa terdapat perbedaan atara nilai rata-rata kualitas pelayanan pada bank konvensional dengan bank syariah, dimana nilai rata-rata kualitas pelayanan bank konvensional lebih tinggi dibandingkan bank syariah $(3,6144>3,5864)^{4}$.

Table 1.1

Data Perbandingan Kualitas Pelayanan dan Kepuasan Nasabah Bank Konvensional dan Syariah pada Provinsi Sumatera Barat

\begin{tabular}{|l|l|l|}
\hline Variable & Bank & Mean \\
\hline \multirow{2}{*}{ Service Quality } & Conventional & 3,6144 \\
\cline { 2 - 3 } & Syariah & 3,5864 \\
\hline \multirow{2}{*}{ Costumer Statifaction } & Conventional & 3,6827 \\
\cline { 2 - 3 } & Syariah & 3,6320 \\
\hline
\end{tabular}

\footnotetext{
${ }^{1}$ Statistik Perbankan Syariah 2018. OJK.go.id.

I. 2 Apriyani ( 2010) “31 Bank Raih Penghargaan Banking Service Excellence Awards 2018". INFOBANK.COM

3 Indratno.B, " Peluang dan Tantangan Perbankan Syariah di Indonesia". MAJALAH ILMIAH EKONOMIKA VOLUME 13 NOMOR 2, Mei 2010 : p:51.).

4 Andespa, R. (2016). Studi Perbandingan Kualitas Pelayanan Industri Perbankan Syariah dengan Konvensional. Sumatera Barat. Al Masraf (Jurnal Lembaga Keuangan dan Perbankan)-Volume 1, No.1, Januari-Juni 2016. P:86.
} 
Sumber: Data Jurnal Perbandingan Kualitas Pelayanan dan Kepuasan Nasabah Bank Konvensional dan Syariah. ${ }^{5}$

Dari Table 1.1. Data Perbandingan Kualitas Pelayanan dan Kepuasan Nasabah Bank Konvensional dan Syariah, dapat dilihat bahwa nasabah bank konvensinal dinyatakan memiliki kualitas pelayanan yang lebih tinggi di bandingkan dengan nasabah Bank Syariah, hal tersebut sangat mempengaruhi keberhasilan suatu bisnis dimana apabila kualitas pelayanan suatu perusahaan jasa di desain dan diimplementasikan dengan baik maka akan sangat mempengaruhi kepuasan pelanggannya sehingga dapat meningkatkan profitabilitas perusahaan tersebut dan bersaing dalam memperluas pangsa pasar.

Kualitas pelayanan berpusat pada upaya pemenuhan kebutuhan dan keinginan pelanggan serta ketepatan penyampaiannya atau dengan kata lain adalah suatu bentuk perbandingan antara harapan dan kenyataan yang diperoleh konsumen. Oleh karena itu kualitas pelayanan adalah item yang sangat penting yang tentu harus diperhatikan di dunia perbankan, meskipun kualitas pelayanan dan kepuasan nasabah adalah suatu hal yang abstrak, tetapi hal tersebut dapat diukur untuk dijadikan acuan perbaikan dalam menentukan strategi yang tepat.

Kualitas harus dimulai dari kebutuhan konsumen dan berakhir pada presepsi konsumen. Terdapat lima determinan kualitas pelanggan yang dapat dirincikan sebagai berikut: (a) keandalan (reability), yaitu kemampuan untuk melaksanakan jasa yang dijanjikan dengan tepat dan terpercaya, (b) ketanggapan (responsiveness), yaitu kemampuan untuk membantu pelanggan dan memberikan jasa dengan cepat, (c) keyakinan (confidance / assurance), yaitu pengetahuan dan kesopanan pegawai serta kemampuan mereka untuk menimbulkan kepercayaan atau keyakinan, (d) empati (empathy), yaitu syarat untuk peduli, memberi perhatian pribadi bagi pelanggan, berwujud (tanggible), yaitu penampilan fasilitas fisik, peralatan, personel, dan media komunikasi. ${ }^{6}$

Untuk mengukur kepuasan pelanggan melalui kualitas layanan yang diberikan PT. Bank Negara Indonesia BNI Syariah KC. Ciputat peneliti akan menggunakan dua metode yaitu metode Costumer Satisfaction Index (CSI), dan metode Importance Performance Analysis (IPA).

Maka atas dasar pemaparan data-data di atas, penulis tertarik mencoba memberikan pemaparan lebih lanjut dan menuangkannya dalam skripsi yang berjudul "Pengukuran Kepuasan Nasabah melalui Kualitas Layanan PT. Bank Negara Indonesia (BNI) syariah KCP. Ciputat dengan Menggunakan Metode Importance Performance Analysis (IPA) dan Metode Costumer Satisfaction Index (CSI)"sehingga menciptakan suatu penilaian puas atau tidaknya suatu layanan yang diterima nasabah pada, dengan membandingkan tingkat kepentingan (harapan) dan tingkat kepuasan (kenyataan) terhadap atribut kualitas pelayanan, atribut-atribut kualitas pelayanan tersebut adalah; berwujud (tanggible), keandalan (reability), daya tanggap (responsiveness), jaminan atau kepastian (assurance), kepedulian (empathy), ditambah fasilitas bank yang ditawarkan.

\footnotetext{
5 Andespa, R. (2016). Studi Perbandingan Kualitas Pelayanan Industri Perbankan Syariah dengan Konvensional. Sumatera Barat. Al Masraf (Jurnal Lembaga Keuangan dan Perbankan)-Volume 1, No.1, Januari-Juni 2016. P:85. ${ }^{6}$ Kothler,1997. Marketing Manajemen:Analysis, Planning,Implementation, and Control, $9^{\text {th }}$. Prentice Hall.
Upper Sadels Riverss. New Jersey
} 


\section{TINJAUAN TEORI}

\section{Pemasaran}

Istilah manajemen pemasaran ${ }^{7}$ adalah analisis, perencanaan, implementasi, dan pengendalian program yang dirancang untuk menciptakan, membangun, dan mempertahankan pertukaran yang menguntungkan dengan pembeli sasaran demi mencapai tujuan organisasi.

\section{Jasa/Pelayanan}

secara definisi jasa itu adalah setiap tindakan atau aktivitas dan bukan benda, yang dapat ditawarkan oleh suatu pihak kepada pihak lain, yang pada dasarnya intangible atau (tidak berwujud fisik), konsumen terlibat aktif dalam proses produksi dan tidak menghasilkan kepemilikan sesuatu. ${ }^{8}$

\section{Kepuasan Pelanggan}

Kepuasan adalah perasaan senang atau kecewa seseorang yang muncul setelah membandingkan antara persepsi atau kesan terhadap kinerja atau hasil suatu produk dan harapan-harapannya. ${ }^{9}$

\section{Kualitas Jasa/Pelayanan}

Kualitas pelayanan berpusat pada upaya pemenuhan kebutuhan dan keinginan pelanggan serta ketetapan penyampaiannya untuk mengimbangi harapan pelanggan. ${ }^{10} \mathrm{Jika}$ layanan yang diterima melampaui harapan pelanggan maka kualitas pelayanan dipresepsikan sebagai kualitas layanan yag ideal. Begitupun sebaliknya jika layanan yang diterima lebih rendah dari harapan pelanggan maka kualitas pelayanan di presepsikan buruk.

\section{METODE PENELITIAN}

\section{Metode Pemilihan Sampel}

Teknik penarikan sampel yang digunakan dalam penelitian ini adalah Non Probability Sampling atau penarikan sampel secara acak dengan menggunakan teknik conveience sampling. Non probability sampling adalah teknik pengambilan sampel yang tidak memberi peluang/kesempatan yang sama bagi setiap unsur anggota populasi untuk dipilih menjadi sample, ${ }^{11}$ dan conveience sampling adalah sebuah kumpulan informasi dari anggota-anggota populasi yang mudah diperoleh dan mampu menyediakan informasi tersebut

Responden dalam penelitian ini adalah nasabah yang datang ke Bank BNI Syariah KCP. Ciputat Tangerang dan bersedia menjadi responden. Penentuan jumlah sampel atau responden yang berukuran besar dan jumlahnya tidak diketahui ditentukan berdasarkan hasil perhitungan menggunakan rumus sebagai berikut (Widiyanto, 2008:19):

\footnotetext{
${ }^{7}$ Kotler .2004. Manajemen Pemasaran 2, Edisi Melenium. Prentice Hall Int'1, New Jersey. Terjemahan PT. Ikrar Mandiri. Jakarta. P:16

${ }^{8}$ Nugraha dkk. 2014. Usulan Peningkatan Kualitas Pelayanan Jasa pada Bengkel "X" Berdasarkan Hasil Matrix Importance-Performance Analysis (Studi Kasus di Bengkel AHASS PD. Sumber Motor Karawang). Jurnal Online Institut Teknologi Nasional 3(1): 221-231

${ }^{9}$ Kotler, 2003. Philip. Marketing Management, $11^{\text {th }}$ Edition. Prentice Hall Int'l, New Jersey. P:138

${ }^{10}$ Simamora, 2003, Memenangkan Pasar dengan Pemasaran Efektif \& Profitable. Cetakan ke: 2. Jakarta: PT Gramedia Pustaka Utama.

${ }^{11}$ Sugiono, 2017. Metode Penelitian Kuantitatif, Kualitatif dan R\&D. Alfabeta. Bandung.
} 


$$
\begin{aligned}
& n=\frac{Z^{2}}{4(\text { Moe })^{2}} \\
& n=\frac{1,96^{2}}{4(0,1)^{2}} \\
& n=\frac{3,8416}{0,04} \\
& n=96,04 \\
& n=96
\end{aligned}
$$

Dimana:

n : Jumlah sampel

$\mathrm{Z} \quad$ : Tingkat keyakinan yang dibutuhkan dalam penentuan sampel 95\%

Pada penentuan ini $\mathrm{Z}$ pada $\alpha=0,5$ adalah 1,96

Moe : Margin Of Error, yaitu tingkat kesalahan yang dapat ditoleransi, ditetapkan sebesar $10 \%$

Berdasarkan perhitungan yang diperoleh diatas, maka jumlah sampel yang diteliti adalah sebesar 96,04 responden. Untuk memudahkan dalam penelitian, maka ditetapkan jumlah sampel sebanyak 100 responden Nasabah BNI Syariah KCP. Ciputat.

\section{Instrument Penelitian}

Adapun instrument penelitian dari penelitian ini, yaitu:

1. Peneliti

Dalam penelitian ini peneliti juga dapat disebut sebagai sumber atau alat dalam penelitian. Untuk melakukan pengumpulan data dari penelitian ini, peneliti menggunakan koesioner (angket). Koesioner (angket) merupakan teknik pengumpulan data yang dilakukan dengan cara memberi seperangkat pertanyaan-pertanyaan tertulis kepada responden untuk menjawabnya. ${ }^{12}$ Dalam kuoesioner ini peneliti mengukur kepuasan nasabah tersebut dengan menggunakan 5 atribut dari kualitas pelayanan yang berupa berwujud (tangible), keandalan (reability), daya tanggap (responsiveness), jaminan atau kepastian (assurance), kepedulian (empathy) pada bank BNI Syariah KCP Ciputat.

2. Koesioner (angket)

Pengukuran kualitas pelayanan dengan 5 atribut terhadap kepuasan pelanggan pada BNI Syariah KCP Ciputat diukur dengan menggunakan koeisioner (angket) dengan mengacu kepada 2 jawaban yaitu kepentingan (harapan) dan kepuasan (kenyataan) yang diterima oleh nasabah yang pilihan jawabannya menggunakan skala likert. Skala likert merupakan alat yang digunakan untuk mengukur instrument yang diguakan untuk mengukur sikap, presepsi dan pendapat seseorang atau sekelompok orang terhadap potensi dan permasalahan suatu objek rancangan suatu produk, proses membuat produk dan produk yang telah dikembangakan atau diciptakan. ${ }^{13}$ Skala likert terdiri dari sangat penting, penting, cukup penting, kurang penting dan tidak penting atau sangat setuju, setuju, cukup setuju, kurang setuju dan tidak setuju dengan skor 1 sampai dengan 5 . Pertanyaan yang diajukan oleh peneliti adalah pertanyaan yang akan memungkinkan nasabah mengekspresikan tingkat pendapat mereka terhadap kualitas pelayanan yang di 
terima di Bank BNI Syariah KCP Ciputat untuk dapat diukur dan diketahui hasilnya melalui 2 opsi jawaban yaitu kepentingan (harapan) dan kepuasan (kenyataan). Kemudian pada pengujian berikutnya setiap pertanyaan yang terdapat pada koesioner pada penelitian ini disebut atribut pelayanan.

Dengan menggunakan skala likert maka variable yang diukur akan dijabarkan menjadi indikator variable. Dimana skala akan diukur dengan skor pada table dibawah ini, yaitu:

Table 3.1

Skala Penilaian Pertanyaan

\begin{tabular}{|c|c|c|c|c|}
\hline No. & $\begin{array}{c}\text { Tingkat Kepentingan } \\
\text { (Harapan) }\end{array}$ & Skor & $\begin{array}{c}\text { Tingkat Kepuasan } \\
\text { (Kenyataan) }\end{array}$ & Skor \\
\hline 1. & Tidak Penting (TP) & 1 & Tidak Puas (TP) & 1 \\
2. & Kurang Penting (KP) & 2 & Kurang Puas (KP) & 2 \\
3. & Netral (N) & 3 & Netral (N) & 3 \\
4. & Penting (P) & 4 & Puas (P) & 4 \\
5. & Sangat Penting (SP) & 5 & Sangat Puas (SP) & 5 \\
\hline
\end{tabular}

Sum ber: Jurn al Onli ne Faku Ekonomi \& Manajemen IPB ${ }^{14}$ ltas

\section{Metode Analisis data}

\section{Uji Validitas}

Uji validitas digunakan untuk mengukur ketepatan suatu item dalam koesioner atau skala, apakah item-item pada koesioner tersebut sudah tepat dalam mengukur apa yang ingin diukur. $^{15}$

\section{Uji Reliabilitas}

Reliabilitas adalah suatu nilai yang menunjukkan konsistensi suatu alat ukur di dalam mengukur gejala yang sama. Hasil dapat ditentukan dengan pedoman jika $r$ alpha $>r$ table maka dinyatakan reliable begitupun sebaliknya jika $\mathrm{r}$ alpha $<\mathrm{r}$ table maka dinyatakan tidak reliable. ${ }^{16}$

\section{Importance Performance Analysist (IPA)}

Pengujian untuk metode ini menggunakan alat pengujian Ms. Excel 2010 dan data yang diambil dan diolah merupakan hasil koesioner yang diperoleh dari nasabah Bank BNI Syariah KC Ciputat berupa tingkat kepentingan (harapan) maupun tingkat kepuasan (kenyataan).

Adapun tahapan pengolahan dengan metode IPA ${ }^{17}$ adalah:

1) Penentuan skor rata-rata atribut tingkat kepentingan dan pelaksanaan

Rumus yang digunakan dalam tahap pertama ini adalah:

14 Jony, W. 2009. Analisis Kepuasan Nasabah Terhadap Mutu Pelayanan Bank Muamalat Indonesia Cabang Bogor. Jurnal Online Ekonomi: Institut Pertanian Bogor. https://repository.ipb.ac.id/handle/123456789/15481.

${ }^{15}$ Ghozali, Imam. 2016 . Aplikasi Anaisis Multivariete dengan Program SPSS 2.3 (Edisi 8). Cetakan ke VIII. Semarang: Badan Penerbit Universitas Diponegoro.

${ }^{16}$ Ghozali, Imam. 2016 . Aplikasi Anaisis Multivariete dengan Program SPSS 2.3 (Edisi 8). Cetakan ke VIII. Semarang: Badan Penerbit Universitas Diponegoro.

${ }^{17}$ Supranto, J. 2011. Pengukuran Tingkat kepuasan pelanggan Untuk Menaikan Pangsa Pasr. Rineka Cipta. Jakarta. P:241 


$$
\overline{X i}=\frac{\Sigma x i}{n} \text { dan } \bar{Y} i=\frac{\Sigma y i}{n}
$$

Keterangan :

$\overline{X i}=$ skor rata-rata tingkat pelaksanaan/realita untuk atribut ke-i

$\bar{Y} i=$ skor rata-rata tingkat kepentingan/harapanuntuk atribut ke-i

$x i=$ jumlah skor tingkat pelaksanaan/realita untuk atribut ke-i

$y i=$ jumlah skor tingkat kepentingan/harapan untuk atribut ke-i

$$
n=\text { jumlah responden }
$$

2) Penentuan skor rata-rata atribut tingkat kepentingan dan pelaksanaan secara keseluruhan dengan rumus yang digunakan adalah:

$X i=\frac{\Sigma \overline{x i}}{k}$ dan $Y i=\frac{\Sigma \overline{x i}}{k}$

Keterangan :

$$
\begin{gathered}
X i=\text { skor tingkat pelaksanaan untuk atribut ke-i } \\
Y i=\text { skor tingkat kepentingan untuk atribut ke-i } \\
\overline{x i}=\text { skor rata-rata tingkat pelaksanaan untuk atribut ke-i } \\
\overline{y i}=\text { skor rata-rata tingkat kepentingan untuk atribut ke-i } \\
k=\text { banyaknya atribut pelayanan }
\end{gathered}
$$

3) Pemetaan atribut

Pada tahapan ini rata-rata setiap atribut dipeta-kan ke dalam Diagram Kartesius dengan kemungkinan 4 posisi kuadran. Posisi setiap atribut tergantung kepada nilai rata-rata atribut dan penjelasan masing-masing kuadran dalam metode IPA adalah sebagai berikut. $^{18}$

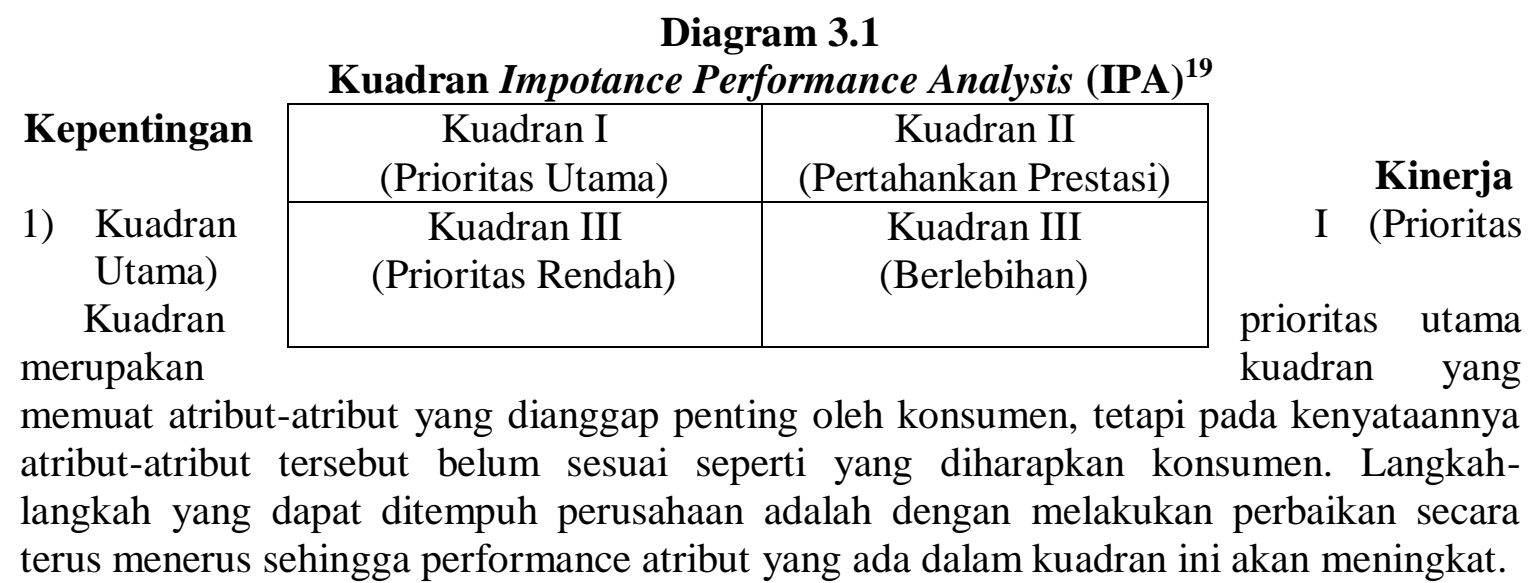

2) Kuadran II (Pertahankan Prestasi)

Kuadran pertahankan prestasi merupakan kuadran yang memuat atribut-atribut yang dianggap penting oleh konsumen dan pelak-sanaan dari atribut-atribut tersebut telah sesuai dengan dirasakannya.Atribut-atribut yang masuk ke dalam kuadran ini harus tetap dipertahankan karena semua atribut tersebut merupakan produk/jasa yang unggul di mata konsumen.

3) Kuadran III (Prioritas Rendah)

18 Rangkuti, F. 2003. Measuring Costumers Statisfaction:Teknik Mengukur \& Strategi Meningkatkan Kepuasan Pelanggan \& Analisis Kasus PLN JP. Jakarta: Gramedia Pustaka Utama.

${ }^{19}$ Supranto, J. 2011. Pengukuran Tingkat kepuasan pelanggan Untuk Menaikan Pangsa Pasar. PT. Rineka Cipta. Jakarta. P:242 
Kuadran prioritas rendah merupakan kuadran yang memuat atribut-atribut yang dianggap kurang penting oleh konsumen dan pada kenyataannya pelaksanaannya tidak terlalu istimewa.Peningkatan atribut-atribut yang masuk ke dalam kuadran ini dapat dipertim-bangkan kembali karena pengaruhnya terhadap manfaat yang dirasakan oleh konsumen sangat kecil.

4) Kuadran IV (Berlebihan)

Kuadran berlebihan merupakan kuadran yang memuat atribut-atribut yang dianggap kurang penting oleh konsumen dan dirasakan terlalu berlebihan.Atribut yang masuk ke dalam kuadran ini dapat dikurangi agar perusahaan dapat menghemat biaya.

\section{Metode Costumer Statisfaction Indexs (CSI)}

Pengujian untuk metode ini menggunakan alat bantu Ms. Excel 2010 dan data yang diambil dan diolah merupakan hasil koesioner yang diperoleh dari nasabah Bank BNI Syariah KC Ciputat berupa tingkat kepentingan (harapan) maupun tingkat kepuasan (kenyataan). Tahapan pengukuran CSI menurut Statford. ${ }^{20}$ adalah:

1) Penginputan data responden nasabah baik rata-rata tingkat kepentingan (harapan) maupun kepuasan (kenyataan) pada alat bantu Ms. Excel 2010

2) Pengukuran tingkat kepentingan (harapan) menggunakan Weighted Factor (WF), yaitu mengubah nilai rataan tingkat kepentingan menjadi angka persentase dari total nilai rataan tingkat kepentigan untuk seluruh atribut yang diuji, sehingga didapatkan weighted factor $100 \%$.

Rumus:

$$
\mathrm{WF}=\frac{y}{\Sigma y i} \times 100 \%
$$

Keterangan:

$W F=$ weight factor

yi $=$ rataan tingkat kepentingan (harapan) untuk atribut ke i

$\sum \mathrm{yi}=$ jumlah rataan tingkat kepentingan (harapan) untuk atribut ke $\mathrm{i}$

3) Pengukuran tingkat Weighted Score (WS), yaitu nilai perkalian antara nilai rataan tingkat kinerja (kepuasan) masing-masing atribut dengan weighted factor masingmasing atribut.

Rumus:

$$
\mathrm{WS}=\frac{\mathrm{WF} \times \mathrm{xi}}{100 \%}
$$

Keterangan:

WS $=$ weight score

$\mathrm{xi}=$ rataan tingkat kepuasan (kenyataan) untuk atribut ke $\mathrm{i}$

4) Mengitung Weighted Total (WT), yaitu menjumlahkanweighted total dari seluruh atribut kualitas jasa.

Rumus:

$$
\mathrm{WT}=\sum \frac{\mathrm{WF} \times \mathrm{xi}}{100 \%}
$$

Keterangan:

$W T=$ weight total

$W F=$ weight factor

$\mathrm{xi}=$ tingkat kepuasan (kenyataan) untuk atribut ke $\mathrm{i}$

${ }^{20}$ Indrawati. 2003. Analisis Kepuasan Nasabah Pembiayaan Terhadap Kualitas Pelayanan BPRS Al Salam Amal Salman Kantor Cabang Leuwilian. https://repository.ipb.ac.id/jspui/bitstream/123456789/18032/3/H08ind.pdf 
5) Menghitung kepuasan pelanggan secara menyeluruh dengan menggunakan Statisfaction Index (SI), yaitu weighted total dibagi skala maksimal yang digunakan dalam penelitian ini kemudian dikali $100 \%$.

Rumus:

$$
\mathrm{SI}=\frac{W T}{n} \mathrm{x} 100 \%
$$

Keterangan:

SI = Statisfaction Index

WT $=$ weight total

$\mathrm{n}=$ jumlah skala maksimal dalam penelitian

6) Pengukuran tingkat kepuasan responden secara menyeluruh menggunakan kriteria tingkat kepuasan pelanggan, adapun kriterianya sebagai berikut:

Tabel 3.3

Kriteria Tingkat Kepuasan Pelanggan

\begin{tabular}{|c|c|}
\hline Skor & Keterangan \\
\hline $0,00-0,34$ & Tidak Puas \\
\hline $0,35-0.50$ & Kurang Puas \\
\hline $0,51-0,65$ & Cukup Puas \\
\hline $0,66-0,80$ & Puas \\
\hline $0,81-1,00$ & Sangat Puas \\
\hline
\end{tabular}

\section{HASIL PENELITIAN DAN PEMBAHASAN}

Analysis Tingkat Kesesuaian/Selisih antara Tingkat Kepentingan dengan Tingkat Kepuasan

Menurut salah satu panduan survey kepuasan nasabah bank syariah menyatakan bahwa optimum score yang diharapkan adalah tidak lebih dari minus 0,50. Artinya atribut-atribut kualitas pelayanan dari bank BNI Syariah KCP. Ciputat telah berhasil memenuhi nilai kesenjangan dari Panduan Survey Kepuasan Nasabah Bank Syariah dengan nilai rata-rata kesenjangan sebesar minus 0,14 yang besarnya tidak melebihi 0 ,

Analysis Kepuasan Nasabah melalui Kualitas Pelayanan Menggunakan Metode Importance Performance Analysis (IPA).

Diagram 4.1

Pengukuran Kepuasan Nasabah 


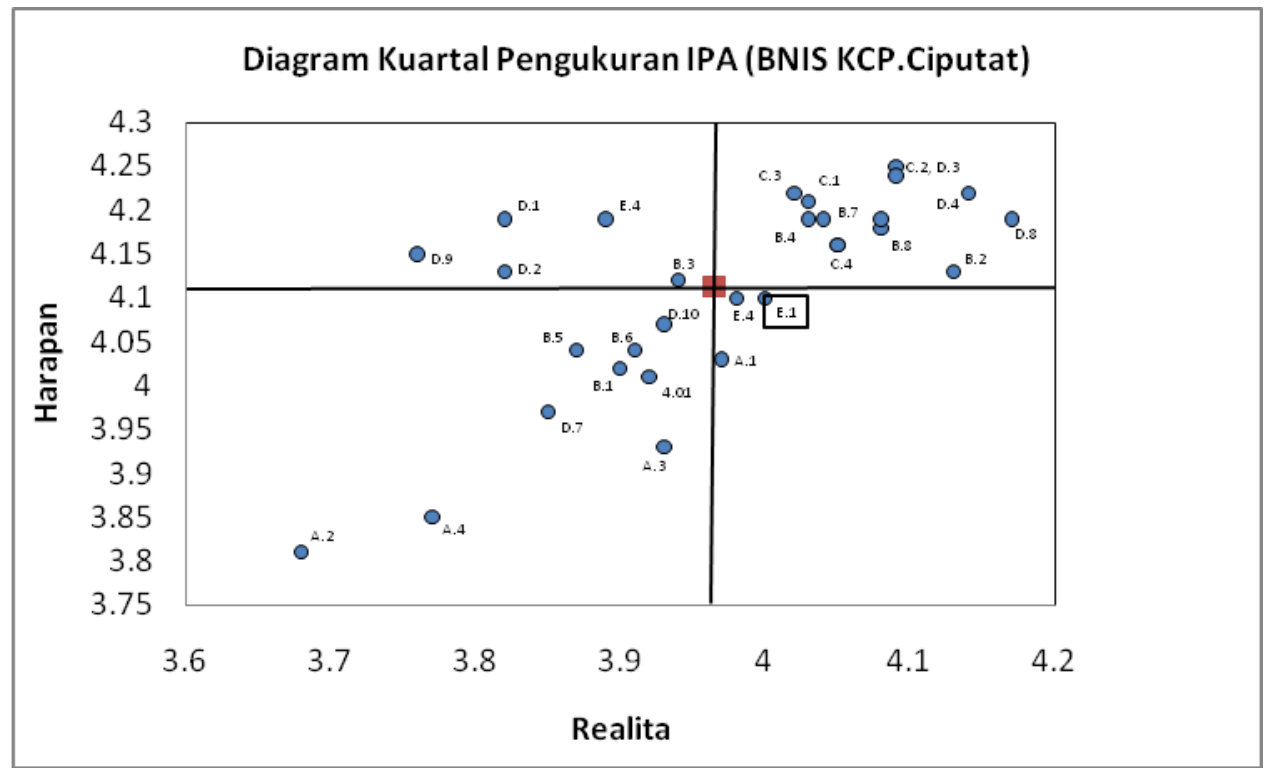

Sumber: data diolah menggunakan alat bantuMs. Excel 2010

Deskripsi hasil diagram-diagram kartesius IPA atas kelima dimensi diatas digabungkan dan dimasukkan kedalam empat kuadran secara bersamaan maka hasilnya seperti dibawah ini:

\section{Kuadran I (Prioritas Utama)}

Pada kuadran ini terdapat lima atribut dari berbagai dimensi keseluruhan, yakni:

1. Karyawan BNI Syariah KCP.Ciputat dapat mengedukasi pentingnya prinsip syariah, (Atribut B3 pada dimensi Reability)

2. Karyawan BNI Syariah KCP.Ciputat menanamkan kepercayaan pada nasabah, (Atribut D1 pada dimensi Assurance)

3. Karyawan BNI Syariah KCP.Ciputat dapat membangun relasi yang baik, (Atribut D2 pada dimensi Assurance)

4. Karyawan BNI Syariah KCP.Ciputat berpengalaman dan memiliki pengetahuan yang luas, (Atribut D9 pada dimensi Assurance)

5. Karyawan tidak memandang status sosial dalam melakuakan pelayanan, (Atribut E1 pada dimensi Empathy)

Jika terdapat atribut pada kuadran ini maka hal itu menandakan bahwa atribut-atribut tersebut memiliki tingkat kepentingan (harapan) yang relative tinggi tetapi kenyataanya masih belum sesuai dengan harapan pelanggan. Atribut-atribut diatas termasuk atribut yang perlu ditingkatkan kualitasnya.

\section{Kuadran II (Pertahankan Prestasi)}

Pada kuadran ini terdapat tiga belas atribut dari berbagai dimensi keseluruhan, yakni:

1. Karyawan BNI Syariah KCP.Ciputat bertanggung jawab atas tugasnya, (Atribut B2 pada dimensi Reability)

2. Karyawan BNI Syariah KCP.Ciputat memiliki pengetahuan yang baik terkait penjelasan produk, (Atribut B4 pada dimensi Reability) 
3. Karyawan BNI Syariah KCP.Ciputat memberikan waktu layanan yang optimal sesuai dengan kebutuhan nasabah, (Atribut B7 pada dimensi Reability)

4. Karyawan BNI Syariah KCP.Ciputat menginformasikan layanan untuk mempermudah transaksi nasabah seperti sms banking, e-banking, m-banking, dll, (Atribut B8 pada dimensi Reability)

5. Karyawan BNI Syariah KCP.Ciputat menghargai ketepatan waktu pelayanan, (Atribut $\mathrm{C} 1$ pada dimensi Ressponsiveness)

6. Karyawan menggunakan bahasa yang mudah dimengerti dalam pelayanan, (Atribut C2 pada dimensi Ressponsiveness)

7. Karyawan BNI Syariah KCP.Ciputat memberi perhatian dan cepat tanggap dalam mengatasi keluhan, (Atribut C3 pada dimensi Ressponsiveness)

8. Karyawan BNI Syariah KCP.Ciputat melayani sesuai dengan urutan, (Atribut C4 pada dimensi Ressponsiveness)

9. Karyawan BNI Syariah KCP.Ciputat bersifat ramah, senyum, sapa, salam terhadap nasabah, (Atribut D3 pada dimensi Assurance)

10. Karyawan BNI Syariah KCP.Ciputat menerapkan sikap mimic wajah yang baik pada saat pelayanan, (Atribut D4 pada dimensi Assurance)

11. Nasabah merasa aman menggunakan produk jasa yang diberikan, (Atribut D5 pada dimensi Assurance)

12. Karyawan BNI Syariah KCP.Ciputat dapat menjaga privasi data nasabah, (Atribut D6 pada dimensi Assurance)

13. Karyawan BNI Syariah KCP.Ciputat mengguankan busana yang sopan sesuai dengan aturan yang diberlakukan, (Atribut D8 pada dimensi Assurance)

Pada kuadran II, atribut-atribut yang masuk pada kuadran ini adalah atribut-atribut yang dianggap telah memuaskan nasabah yang berkunjung sehingga atribut-atribut tersebut patut untuk dipertahankan, tetapi untuk jangka waktu panjang alangkah baiknya jika atribut-atribut tersebut lebih ditingkatkan kualitas layanannya agar tidak tertinggal dari para pesaing lainnyadengan.

\section{Kuadran III (Prioritas Rendah)}

Pada kuadran ini terdapat sembilan atribut dari berbagai dimensi keseluruhan, yakni:

1. BNI Syariah KCP.Ciputat memiliki desain interior yang menarik, (Atribut A2 pada dimensi Tanggible)

2. Produk dan jasa pada BNI Syariah KCP.Ciputat beragam dan sesuai dengan kebutuhan, (Atribut A3 pada dimensi Tanggible)

3. BNI Syariah KCP.Ciputat menyediakan alat promosi yang menarik (brosur, pamphlet, iklan, banner,dll), (Atribut A4 pada dimensi Tanggible)

4. Penyelesaian pengajuan produk pada BNI Syariah KC.Ciputat dikerjakan dengan cepat dan tepat, (Atribut B1 pada dimensi Reability)

5. Bank BNI Syariah KCP.Ciputat patuh terhadap prinsip kesyariahannya, (Atribut B5 pada dimensi Reability)

6. Bank BNI Syariah KCP.Ciputat memiliki citra baik dimata masyarakat luas, (Atribut B6 pada dimensi Reability)

7. Bank BNI Syariah KCP.Ciputat menepati janji termasuk iklan dan promosi yang diberikan, (Atribut D7 pada dimensi Assurance) 
8. Karyawan BNI Syariah KCP.Ciputat memberikan saran-saran yang relevan sesuai dengan kebutuhan nasabah, (Atribut D10 pada dimensi Assurance)

9. Nasabah merasa nyaman dengan interior ruang tunggu, toilet, mesin pendingin (AC), dsb, (Atribut E3 pada dimensi Empathy)

Atribut-atribut yang masuk pada kuadran III ini merupakan atribut yang dapat dianggap kurang penting karena atribut-atribut tersebut memiliki nilai tingkat kepentingan (harapan) yang rendah dari pihak nasabah meskipun kepuasannya (realita) yang diterima nasabah relative baik.

Meskipun atribut-atribut pada kadran ini tidak terlalu dinaggap penting, bukan berarti atribut tersebut tidak perlu diperhatikan. Bisa jadi dalam jangka pendek atribut-atribut ini tidak begitu berpengaruh terhadap performa bank tersebut tetapi dalam kurun waktu jangka panjang dan bertambahnya pesaing bank tersebut dan semakin beragam pelayanan baru yang ditawarkan para pesaing, maka atribut-atribut tersebut dengan seberjalannya waktu dapat dianggap penting bagi nasabah yang menerima pelayanan.

Oleh karna itu alangkah baiknya jika tetap diadakan perbaikan pada kuadran III agar tidak terjadi ketertinggalan atau penurunan kualitas layanan dari pelayanan yang diberikan.

\section{Kuadran IV (Berlebihan)}

Pada kuadran ini terdapat tiga atribut dari berbagai dimensi keseluruhan, yakni:

1. BNI Syariah KCP.Ciputat memperhatikan kenyamanan dan kebersihan lingkungan, (Atribut A1 pada dimensi Tanggible)

2. Lokasi kantor/ATM dapat mudah dijangkau nasabah, (Atribut E1 pada dimensi Empathy)

3. Karyawan KCP.Ciputat siap sedia mendengarkan keluhan dan saran yang diberikan nasabah, (Atribut E4 pada dimensi Empathy)

Atribut-atribut yang masuk di dalam kuadran IV adalah atribut-atribut yang sudah dianggap memuaskan bahkan melebihi harapan. Atribut-atribut ini dianggap berlebihan karena memiliki tingkat kepuasan yang relative tinggi, sehingga alangkah baiknya jika biaya yang dikeluarkan untuk peningkatan kualitas pelayanan pada kuadran ini lebih dikurangi sehingga dapat menunjang perbaikan pada atribut di kuadran lainnya yang membutuhkan.

\section{Analysis Kepuasan Nasabah melalui Kualitas Pelayanan Menggunakan Metode Costumers Statisfaction Index (CSI)}

Hasil CSI untuk atribut kualitas pelayanan yang dilakukan oleh bank BNIS KCP. Ciputat sebesar 79,34\%. Nilai tersebut berada pada rentang nilai CSI yaitu antara 0,660,80 yang berarti bahwa nasabah telah merasa puas atas kinerja BNIS KCP. Ciputat.Dengan kepuasan nasabah terhadap kualitas pelayanan yang diberikan, diharapkan pihak manajemen dapat terus meningkatkan kinerjanya agar lebih memaksimalkan lagi tingkat kepuasan nasabah dikemudian hari.

\section{KESIMPULAN DAN SARAN}




\section{Kesimpulan}

Berdasarkan analisis dan pembahasan yang tealah di paparkan pada bab sebelumnya, maka dapat diambil kesimpulan sebagai berikut:

1. Kepuasan nasabah pada bank BNI Syariah KCP. Ciputat dapat dilihat dari nilai Costumer Satisfaction Index (CSI) sebesar 79,34\%. Niai tersebut berada pada nilai kriteria 0,66-080 yang berarti nasabah telah merasa puas aras pelayanan dari bank BNI Syariah KCP. Ciputat.

2. Berdasarkan pengukuran menggunakan metode Importance and Performance Analysis (IPA) atribut pada tiap dimensi yang diteliti masuk ke dalam empat kuadran:5 atribut dikategorikan sebagai "prioritas perbaikan", dan 13 atribut dikategorikan sebagai "pertahankan prestasi". Selanjutnya, ada 3 atribut yang dikategorikan "berlebihan" dan 9 atribut adalah sebagai "prioritas rendah".

3. Kemudian rata-rata nilai kesesuaian/selisih dari seluruh atribut pelayanan Bank Bank BNI Syariah KCP. Ciputat adalah minus 0,14.

\section{Saran}

Bagi pihak manajemen di Bank Syariah dapat menggunakan hasil penelitian ini sebagai bahan informasi untuk dijadikan acuan perbaikan atribut apa saja yang menjadi prioritas I yang tetntu harus dijadikan prioritas dalam perbaikan. Kemudian agar lebih menghemat biaya, alangkah baiknya jika pengalokasian atribut-atribut yang masuk dalam kuadran III dan IV terlebih dahulu di peruntukan untuk atribut prioritas yaitu atribut I. Atribut-atribut lainnya tetap dilaksanakan pelayanananya tetapi harus di prioritaskan lebih pada tingkat kepentingannya sehingga tidak berlebihan.

\section{DAFTAR PUSTAKA}

Andespa, R. 2016. Studi Perbandingan Kualitas Pelayanan Industri Perbankan Syariah dengan Konvensional. Sumatera Barat. Al Masraf (Jurnal Lembaga Keuangan dan Perbankan)-Volume 1, No.1, Januari-Juni 2016.

Apriyani. 2018. 31 Bank Raih Penghargaan Banking Service Excellence Awards 2018. https://infobanknews.com/31-bank-raih-penghargaan-banking-service-excellence-awards$\underline{2018 /}$

Ghozali, Imam. 2016 . Aplikasi Anaisis Multivariete dengan Program SPSS 2.3 (Edisi 8). Cetakan ke VIII. Semarang: Badan Penerbit Universitas Diponegoro

Indratno.B, " Peluang dan Tantangan Perbankan Syariah di Indonesia". MAJALAH ILMIAH EKONOMIKA VOLUME 13 NOMOR 2, Mei 2010 : p:51.).

Indrawati, 2008. Analisis Kepuasan Nasabah Pembiayaan Terhadap Kualitas Pelayanan BPRS Al Salam Amal Salman Kantor Cabang Leuwiliang. Skripsi pada Departemen Manajemen, Fakultas Ekonomi dan Manajemen IPB, Bogor. https://repository.ipb.ac.id/jspui/bitstream/123456789/18032/3/H08ind.pdf

Jony, W. 2009. Analisis Kepuasan Nasabah Terhadap Mutu Pelayanan Bank Muamalat Indonesia Cabang Bogor. Jurnal Online Ekonomi: Institut Pertanian Bogor. https://repository.ipb.ac.id/handle/123456789/15481 
Kotler, Philip.1997. Marketing Manajemen:Analysis, Planning,Implementation, and Control, $9^{\text {th }}$. Prentice Hall. Upper Sadels Riverss. New JerseyJersey, Jakarta: PT. Ikrar Mandiri.

Kotler, Philip.2004.Manajemen Pemasaran 2, Edisi Melenium. Prentice Hall Int'1, New

Nugraha, R., A. Harsono, dan H. Adianto. 2014. Usulan Peningkatan Kualitas Pelayanan Jasa pada Bengkel "X" Berdasarkan Hasil Matrix Importance-Performance Analysis (Studi Kasus di Bengkel AHASS PD. Sumber Motor Karawang). Jurnal Online Institut Teknologi Nasional 3(1): 221-231.

OJK. Statistik Perbankan Syariah 2018. https://www.ojk.go.id/id/kanal/syariah/data-danstatistik/statistik-perbankan syariah/Default.aspx

Rangkuti, F. 2003. Measuring Costumers Statisfaction:Teknik Mengukur \& Strategi Meningkatkan Kepuasan Pelanggan \& Analisis Kasus PLN JP. Jakarta: Gramedia Pustaka Utama.

Sugiono. 2013. Metode Penelitian Kuantitatif, Kualitatif dan R\&D. Alfabeta. Bandung.

Sugiono, 2015. Metode Penelitian Kuantitatif, Kualitatif dan R\&D. Alfabeta. Bandung.

Sugiono, 2017. Metode Penelitian Kuantitatif, Kualitatif dan R\&D. Bandung: Alfabeta

Simamora, B. 2003. Memenangkan Pasar dengan Pemasaran Efektif \& Profitable. Cetakan ke: 2. Jakarta: PT Gramedia Pustaka Utama

Supranto, J. 2011. Pengukuran Tingkat kepuasan pelanggan Untuk Menaikan Pangsa Pasar. PT.Rineka Cipta. Jakarta. 